\title{
PACE UNIVERSITY'S FOCUS ON STUDENT SATISFACTION WITH STUDENT SERVICES IN ONLINE EDUCATION
}

\author{
Dr. David Sachs \\ Professor Nancy Hale
}

\begin{abstract}
In 1999, Pace University was awarded a \$1,000,000, three-year FIPSE Learning Anytime Anywhere Program (LAAP) Grant. The grant focuses on three areas: online testing, enhanced student support services, and mentoring. Funding from the LAAP grant has enabled the University to greatly enhance the student services that are provided to online students. The focus has been primarily on students who are within the NACTEL program, an online AS in Telecommunications degree offered to individuals working for Citizens Communications, Qwest, SBC and Verizon, and who are members of the Communications Workers of America (CWA) and the International Brotherhood of Electrical Workers (IBEW). FIPSE funding has enabled the University to extensively survey students in the program, by an outside evaluator. These surveys are all online, are tabulated instantly, and provide a steady stream of feedback to administrators and faculty who are involved in the program. In addition, FIPSE funding has made it possible to hire individuals who on a regular basis attend to how to best provide enhanced student support services for online students. As new ideas are developed, they are implemented as quickly as possible. This paper will present some of the research findings, and will also provide details about the changes to the NACTEL program that have occurred as a direct result.
\end{abstract}

\section{KEYWORDS}

Student Support Services, Continuous Improvement, Online Education

\section{ENHANCED STUDENT SUPPORT SERVICES OVERVIEW}

For students in the NACTEL project, student support services focus on a variety of areas. For the past year, these have included:

\section{A. Surveying Students}

- Streamlined the surveying process (not too many surveys, too often)

- Surveys to new applicants

- Surveys to new students

- Surveys to returning students

\section{B. Research}

- Continued research of other online learning sites

- Focused on the application process

- Focused on the advisement process 
- Focused on the registration process

- Focused on tuition assistance for online students

- Focused on financial aid, and

- General Customer Service or Virtual Service

\section{Web Site Redevelopment}

- Created a sample course

- Prepared a template for staff and faculty bios

- Redesigned the database for course descriptions

- Developed more attractive formatting of the Web site

- Planned for archiving historical information by semester.

- Assisted with the initial development of the Student Information Center

- Beginning to work on online, self-paced Tech Help Tutorials and for online self-paced Study Guides

\section{Tuition}

- Designed automated response email regarding tuition, fees and how to get contact information for Tuition Assistance from companies.

- Kept Tuition Assistance information for students up-to-date.

\section{E. Communication}

- Streamlined and updated all existing communications, targeting both prospective and current students

\section{F. Process Improvement}

- Identified breakdowns, and prepared a Process Improvement Review

- In the process of researching contact management software

\section{G. Online Testing}

- Fully implemented the proctoring program throughout NACTEL courses

- Continued revision and development of proctoring requirements, guidelines and documents

- More proactive guidance of students throughout the proctor application process

- Standardized various components of the proctored exams (delivery/return methods, exam deadlines)

- New initiatives to provide students with access to proctored exam information directly within their courses

- Continued evaluation of both students and proctors using improved online survey methodologies (in collaboration with IOTA Solutions)

- Monitoring proctored examination status in all courses

- Ongoing communication with students/proctors by providing them with proctor exam 
information, dealing with conflicts that arise in terms of scheduling an exam and tracking exam completion

- Assisted students in finding a proctor when necessary

- Launched a new online proctor database and application form

\section{NACTEL STUDENT SURVEYS}

NACTEL students are surveyed in a number of ways. Within their courses, students are surveyed by Pace University after 5 weeks, after 10 weeks, and then after the conclusion of their courses (15 weeks).

In addition, and most pertinent to this case study, students are surveyed by IOTA Solutions, an external evaluator hired specifically to provide online surveys to students. A wide array of surveys has been administered to students. All exams and results are located at: http://www.iotasolutions.com/pace/ and are tabulated and reported almost instantaneously.

The NACTEL Program Improvement Survey focuses on five major areas:

1. The Web Site

2. The Application Process

3. The Registration Process

4. The Course Experience

5. Overall satisfaction with the program

In addition, a second set of surveys focuses exclusively on the Online Testing part of the program. Students are required to have proctors who must verify that they have taken their examinations under the test-taking procedures that were specified by their instructors. There are specific procedures for doing this, all of which are outlined on the Pace University/NACTEL Web site at:

https://support.csis.pace.edu/nactel/gotoclass/proctoring.cfm

As might be imagined, students have a fair amount of anxiety about the proctoring process, and it is extremely important that it go smoothly and effectively. With that in mind, all students and proctors are surveyed about the process, on a continuous basis. Questions about the online testing process focus on:

- Was the proctored exam information clear and understandable?

- How easy or hard was the scheduling process?

- How difficult or easy was it to access the actual examinations?

- Was it necessary to pay the proctor a fee?

- Did the students or the proctors encounter any problems?

- How did the overall proctored examination process go?

- Are there any suggestions about how to improve the process?

Again, the overall thrust of the surveys (which are sent to both the students and the proctors) is to ensure that the services that are being provided are working well and effectively for all concerned. 


\section{THE STUDENT INFORMATION CENTER}

A new feature this year, that continues to improve the services being provided to students in the program, is the Student Information Center. This center, which is located at: http://support.csis.pace.edu Inactel/infocenter/index.cfm provides students with a wonderful array of resources, quickly and easily. Students can check on (and modify) a wide array of information at this site:

- They can check on all of their personal information.

- They can check on all of their company information.

- They can take their Math Assessment exam, and then see what the score is.

- They can check on their Prior Learning Records.

- They can check on their course registrations.

- And if need be, they can add or drop a course and they can request a course transcript.

Automating access to all of this information has dramatically increased the satisfaction level of students in the program. And, it has also reduced the workload (and the opportunity for error) for NACTEL support staff.

\section{TECHNICAL SUPPORT AND THE ONLINE STUDENT SEMINAR}

Students in the NACTEL program are, for the most part, individuals working on their own, at great distances from the Pace University campuses. All involved are concerned that hardware and software issues should not get in the way of the educational process. Towards that end, students are provided with technical support as part of their involvement in the program.

First of all, there has been a focus on providing information and resources to the students in a format that is accessible using a 56K modem, and dial-up connectivity to the Internet, with a reasonably current (version 4) browser. In addition, there has been a strong emphasis on getting the students set up technically, before they are in any of their academic courses. Therefore, all entering students are required to take the Online Student Seminar. This one credit course, which takes approximately two weeks to complete, introduces students to all of the technical requirements that are included in the NACTEL program.

In the Online Student Seminar, students encounter:

- Microsoft Office 2000 (Word, Access, PowerPoint \& Excel)

- RealAudio

- HorizonLive

- Adobe Acrobat

- Shockwave

- BlackBoard 5.5 - the course management software being used

- Downloading and installing software

Self-tests for all of these are included in the Online Student Seminar. Students encounter examples of each of the programs, and are given a quiz about the content contained within the examples. In this way, 
they know, and we know, whether or not they are ready to continue in the program. If students need additional help or assistance, it is provided by their instructor or by one or several of the technical support students who answer the NACTEL technical support phone lines and email.

HorizonLive includes a wonderful set of tests within the software. It provides the students with examples of all that they are likely to encounter, and walks them through the process step-by-step.

Again, the focus of all of this has been on how to provide support services to students who may be encountering technical support issues, on their own, for the first time. The underlying premise is that there must be support for the students. And, it is better to localize the need for this support in one course, early in the program. This has enabled most faculty members (and students) the luxury of not having to deal with such problems. It has also meant that when technical problems are encountered, it is early on in the program, in a course that is pass/fail, so there is little or no additional pressure on the students.

\section{TUTORING SERVICES AND SMARTHINKING}

Pace University's NACTEL program provides students with the opportunity to obtain an AS in Telecommunications. This particular degree requires students to be competent in fundamental math skills. Consequently, there is a math assessment given to all students prior to their entry into the program. Most students take the two math courses that are offered, before taking any of the electronics and telecommunications courses within the degree.

Some of our students need extra help and support while they are taking their math courses. For some of them, it has been many years since they last took math courses. For others, it is probably fair to say that they were not strong math students earlier on in their academic careers.

The concern was (and is) how to provide these students, who tend to do much of their work during the evening or on weekends, with the math support that they need. Consequently, Smarthinking has been engaged to provide tutoring services to math students. The services are available for free to the students and they are available online into the early morning hours. Students are provided with information that tells them where to find the help, and that gives them the userid and password that they need to enter the Smarthinking Web site.

Not all students need the tutoring services. However, for those who do, this has proven to be an invaluable student support service. Some students have told us in their final course evaluations, that without the Smarthinking tutoring services, they would have been unable to successfully pass the math courses.

\section{CONCLUSION}

Pace University has focused on student satisfaction in the NACTEL program since this program's inception. Students are asked early and often (sometimes too often) about how they are doing in their various courses and with our Web site. Methods have been developed, and continue to be developed, that provide faculty and administrators responsible for the program with information in a timely and efficient fashion. Whenever possible, timely responses are made to the information that students provide.

There has been a focus on how to continually improve all of the processes that students encounter while 
studying in the program. In addition, there is a continual flow of information back and forth between the students and the faculty about the courses that are being taught. Within the realm of reason, courses have been modified and (hopefully) improved, in response to student feedback.

The goal has been (and continues to be) to keep the student satisfaction level high within the NACTEL program.

\section{RECENT SURVEY}

The following pages include a recent survey (September 2001) of students in the NACTEL program. The survey provides a good sample of the kind of information that has been collected throughout the three years that the NACTEL program has been in full-scale operation. The survey focuses on five areas:

- The Registration Process

- Online Education

- Online versus Traditional Education

- The Pace University/NACTEL Program

- Demographic Information

Surveys such as this one, throughout the year, are used for continual improvement of the program. It is pleasing to note that for the most part (98\%) students responded that they are either very satisfied or satisfied with the overall program. Obviously, there are specific areas that continue to need attention, but overall it appears that the Pace University/NACTEL program is doing well.

\section{ACKNOWLEDGEMENTS}

Pace University has been fortunate to receive funding through the FIPSE/LAAP program. Funds received from this program have been used to provide significant enhanced student services as well as external evaluation of the Pace University/NACTEL program. Lorraine Kleinwaks, the FIPSE Program Officer, has provided tremendous support for the past two years.

\section{ABOUT THE AUTHORS}

David. Sachs is Assistant Dean and Professor of Office Information Systems in Pace University's School of Computer Science and Information Systems. As Assistant Dean, he has been actively involved in the development and implementation of computer science and telecommunications courses for the corporate community since 1984. As director of the Pace Computer Learning Center, Dr. Sachs is responsible for the many hundreds of days of personal computer, computer science, and telecommunications education that are provided each year to corporations throughout the United States and around the world such as AT\&T, IBM, MCI, PepsiCo, The Reader's Digest, Prodigy and others. Dr. Sachs works closely with teachers, administrators and others to think about the most effective ways to introduce technology into public and private schools. Most recently, he has been actively involved in the development of courses to be taught asynchronously over the Internet and the World Wide Web. Dr. Sachs is co-director of the NACTEL project (see http://csis.pace.edu/nactel).

Contact: Dr. David Sachs, Assistant Dean, Pace University, School of Computer Science \& Information Systems, 1 Martine Avenue, White Plains, NY 10606; Phone: (914) 763-8820; Fax: (914) 763-9324; Email: $\underline{\text { dsachs@pace.edu }}$ 
Nancy Hale is Chairperson of the Technology Systems Department and has curricula and staffing responsibilities for the department's degrees and certificate programs. She has developed curricula and program designs that support the special needs of the adult learner. Prof. Hale was instrumental in the development of CLOUT, an intensive employment-directed education program established in 1991. Professor Hale is co-director of the NACTEL program. As such, she is responsible for the curriculum development, faculty development, and overall student satisfaction with the program. Prof. Hale has co authored two books in end-user computing and regularly presents at conferences on topics related to end user computing and distance education.

Contact: Professor Nancy Hale, Chairperson, Pace University, School of Computer Science \& Information Systems, 1 Martine Avenue, White Plains, NY 10606; Phone: (914) 422-4464; Fax: (914) 989-8640; Email: nhale@ pace.edu 